\title{
Delays in diagnosis and treatment of pulmonary tuberculosis in patients seeking care at a regional referral hospital, Uganda: a cross sectional study
}

Winters Muttamba ${ }^{1,3^{*}}$ (D) Samuel Kyobe ${ }^{2}$, Alimah Komuhangi ${ }^{3}$, James Lakony ${ }^{4}$, Esther Buregyeya ${ }^{5}$, Eldad Mabumba ${ }^{6}$ and Robert K. Basaza ${ }^{3,7}$

\begin{abstract}
Objective: A cross-sectional survey involving 134 pulmonary TB patients started on TB treatment at the TB Treatment Unit of the regional referral hospital was conducted to ascertain the prevalence of individual and health facility delays and associated factors. Prolonged health facility delay was taken as delay of more than 1 week and prolonged patient delay as delay of more than 3 weeks. A logistic regression model was done using STATA version 12 to determine the delays.

Results: There was a median total delay of 13 weeks and 110 (82.1\%) of the respondents had delay of more than 4 weeks. Patient delay was the most frequent and greatest contributor of total delay and exceeded 3 weeks in 95 (71.6\%) respondents. At multivariate analysis, factors that influenced delay included poor patient knowledge on TB (adjOR 6.904, 95\% Cl 1.648-28.921; $p=0.04$ ) and being unemployed (adjOR 3.947, 95\% Cl 1.382-11.274; $p=0.010$ ) while being female was found protective of delay; adjOR 0.231 , 95\% $\mathrm{Cl} 0.08-0.67 ; \mathrm{p}=0.007$ ). Patient delay was the most significant, frequent and greatest contributor to total delay, and factors associated with delay included being unemployed, low knowledge on TB while being female was found protective of delay.
\end{abstract}

Keywords: Individual delay, Health facility delay, Pulmonary tuberculosis, Hospital set up, Quality of care, Uganda

\section{Introduction}

Tuberculosis (TB) causes devastating effects among millions of people every year. In 2017, 10 million people developed TB disease and an estimated 1.3 million deaths among HIV negative TB patients and 300,000 deaths among HIV co-infected TB patients were recorded [1].

Uganda is a high HIV/TB prevalent country and just like most sub-Saharan countries, TB control has been complicated by the high HIV prevalence [2]. Delay in presentation, together with delay in making a diagnosis and initiation of treatment is responsible for the increased morbidity and mortality from TB. This is

*Correspondence: muttamba@gmail.com

${ }^{1}$ Makerere University Lung Institute, Makerere University College of Health Sciences, Kampala, Uganda

Full list of author information is available at the end of the article coupled with increased transmission rates in the community [3]. Prompt diagnosis and early initiation of treatment remain key strategies in TB prevention and control. It is thus important that the various types of delays and their underlying factors are well studied if the World Health Organization (WHO) post 2015 strategy and targets are to be realized. This study set out to ascertain the prevalence of individual and health facility delays and associated factors among pulmonary TB patients at Mbale Regional Referral Hospital in Eastern Uganda.

\section{Main text Methods}

A cross sectional survey involving all consenting adult patients with pulmonary $\mathrm{TB}$, and started on $\mathrm{TB}$ treatment at Mbale Regional Referral Hospital TB treatment 
unit Uganda in the period September 2015 to February 2016. Importantly, this facility had benefited from country wide roll out of GeneXpert technology that started in 2011.

Clients that had started treatment in the 3 months preceding or during the study were recruited from the TB Unit as they initiated treatment or came back for their drug refill. The study excluded clients that were too ill to respond. A structured interviewer-administered questionnaire was used, and this was adapted from a previous study on TB diagnosis delay in Uganda [4]. Patient delay was defined as the time from the onset of a TB cardinal symptom (cough lasting more than 2 weeks, persistent fevers, noticeable weight loss, excessive night sweats) to the first visit to a health care provider (HCP). Prolonged patient delay was defined as a period of more than 3 weeks. Health facility delay was defined as the time taken from first visit to a HCP up to time of TB diagnosis. Prolonged health facility delay was defined as a delay of more than 1 week. Total delay was taken as the sum of patient delay and health facility delay. Treatment delay was taken as the duration from when the time the diagnosis was made to when the patient was initiated on treatment. A family was used to mean people living under the same roof.

Data gathered were entered into Epi-data software version 2.0.8.56 and exported to Stata software version 12 for analysis. Bivariate analysis using Fishers test was performed on the variables and total delays. Fishers exact test was done given the small numbers under the categories. To ensure more power, we collapsed some categories (occupation, education, action taken at consultation and second health facility consulted) to be able to perform a multivariate analysis of the variables found significant using fishers test.

The study was approved by the Institutional Ethics Review Boards at International Health Sciences University and Mbale Regional Referral Hospital (IRB approval number Number REIRC IN-COM 125/2015).

\section{Results}

Social demographic characteristics of the respondents are presented in Table 1. A total of 134 adults were enrolled into the study. Of these, 61 (45.5\%) were male and median age of respondents was 28 years. The median family size was 4 with a range of 1-19.

The distribution of delays, individual and health facility factors associated with delay analyzed using Fishers test and logistical regression are presented in Table 2. Median total delay was 13 weeks, with a large total delay of more than 4 weeks in $110(82.1 \%)$ respondents. Patient delay exceeded 3 weeks in 96 (71.6\%) respondents, and median patient delay was 11 weeks. Health facility delay exceeded
Table 1 Socio-demographic and access characteristics of respondents

\begin{tabular}{lc}
\hline Characteristic & No. patients (\%) \\
\hline Age, mean & 32 \\
Sex & \\
Male & $61(45.5)$ \\
Female & $73(54.5)$ \\
Highest education level attained & \\
University or higher & $8(6.0)$ \\
Primary/middle/secondary & $115(85.8)$ \\
Illiterate & $11(8.2)$ \\
Occupation & \\
Technical/professional & $20(14.9)$ \\
Peasant & $69(51.5)$ \\
Student & $29(21.6)$ \\
Unemployed & $16(12.0)$ \\
Marital status & \\
Married & $40(29.9)$ \\
Single & $52(38.8)$ \\
Divorced/separated & $34(25.4)$ \\
Widowed & $8(5.9)$ \\
History of smoking & \\
Never & $98(73.1)$ \\
Current smoker & $1(0.8)$ \\
Quit smoking & $35(26.1)$ \\
Number of household members & \\
1 1 & $10(7.6)$ \\
Residence & $124(92.4)$ \\
Urban & \\
Reri-urban & $58(43.3)$ \\
Homeless/displaced & $46(34.3)$ \\
\hline
\end{tabular}

1 week in 59 (44.0\%) respondents, with median being 1 week. Treatment delay was witnessed in 74 (58.7\%) respondents.

At bivariate analysis, factors associated with delay were male gender with being female being protective $(\mathrm{p}=0.025)$, being a professional/technical worker $(p=0.001)$, being married $(p=0.022)$, low knowledge on TB $(p=0.001)$, having a second consultation from a public facility $(p=0.007)$, poorly equipped health facility as judged by patient $(\mathrm{p}=0.007)$ and having only sputum examination requested $(\mathrm{p}=0.046)$. At multivariate analysis, factors that influenced delay included poor patient knowledge on TB $(\mathrm{p}=0.04)$ and being unemployed $(p=0.010)$. The median health facility delay was one (1) week. Health facility delay was associated with action taken at consultation, and when both Xray in addition to sputum was done, the number with a delay reduced to $73.5 \%$ (39/53); i.e. a reduction of $16.1 \%$. 
Table 2 Distribution of delays and predictors of delay

\begin{tabular}{|c|c|c|c|}
\hline Total delay & n (\%) & \multicolumn{2}{|l|}{ Median } \\
\hline Delay (> 4 weeks) & 110 (82.1) & \multicolumn{2}{|l|}{13 weeks } \\
\hline No delay (<4 weeks) & \multicolumn{2}{|l|}{$24(17.9)$} & \\
\hline \multicolumn{4}{|l|}{ Health facility delay } \\
\hline Delay (> 1 week) & $59(44.0)$ & \multicolumn{2}{|l|}{1 week } \\
\hline No delay (<1 week) & \multicolumn{2}{|l|}{$75(56.0)$} & \\
\hline \multicolumn{4}{|l|}{ Patient delay } \\
\hline Delay (> 3 weeks) & $96(71.6)$ & \multicolumn{2}{|l|}{11 weeks } \\
\hline No delay ( $<3$ weeks) & \multicolumn{2}{|l|}{$38(28.4)$} & \\
\hline \multicolumn{4}{|l|}{ Treatment delay } \\
\hline Delay (>0 days) & $74(58.7)$ & \multirow[t]{2}{*}{1 day } & \\
\hline No delay ( 0 days) & $52(41.3)$ & & \\
\hline \multicolumn{4}{|c|}{ Factors associated with prolonged delay } \\
\hline \multirow[t]{2}{*}{ Variable } & \multicolumn{2}{|c|}{ Total delay } & \multirow{2}{*}{$\begin{array}{l}\text { p-values } \\
\text { (Fishers } \\
\text { test) }\end{array}$} \\
\hline & Yes & No & \\
\hline \multicolumn{3}{|l|}{ Sex } & $0.025^{* *}$ \\
\hline Female & $65(89.0)$ & $8(11.0)$ & \\
\hline Male & $45(73.8)$ & $16(26.2)$ & \\
\hline \multicolumn{3}{|l|}{ Occupation } & $0.001^{* *}$ \\
\hline Technical/professional & $20(100)$ & $0(0)$ & \\
\hline Peasant & $58(84.1)$ & $11(15.9)$ & \\
\hline Student & $17(58.6)$ & $12(41.4)$ & \\
\hline Unemployed (or HW) & 15 (93.8) & $1(6.2)$ & \\
\hline \multicolumn{3}{|l|}{ Marital status } & $0.022^{* *}$ \\
\hline Married & $37(92.5)$ & $3(7.5)$ & \\
\hline Single & $36(69.2)$ & $16(30.8)$ & \\
\hline Divorced/separated & $30(88.2)$ & $4(11.8)$ & \\
\hline Widowed & $7(87.5)$ & $1(12.5)$ & \\
\hline Household size & & & 0.361 \\
\hline Education level & & & 0.699 \\
\hline University or higher & $6(75)$ & $2(25)$ & \\
\hline Primary/middle/secondary & $94(81.7)$ & $21(18.3)$ & \\
\hline Illiterate/read and write & $10(90.9)$ & $1(9.1)$ & \\
\hline Residence & & & 0.336 \\
\hline Urban & $48(82.8)$ & $10(17.2)$ & \\
\hline Peri-urban & $40(87.0)$ & $6(13.0)$ & \\
\hline Rural & $22(73.3)$ & $8(28.7)$ & \\
\hline Smoking & & & 0.835 \\
\hline Never & $81(82.7)$ & $17(17.3)$ & \\
\hline Current smoker & $1(100)$ & $0(0)$ & \\
\hline Quit smoking & $28(80.0)$ & $7(20)$ & \\
\hline Stigma & & & 0.019 \\
\hline Health facility whom you sought c & & & $0.007^{* *}$ \\
\hline TB centre & $22(64.7)$ & $12(35.3)$ & \\
\hline Public hospital/outpatient clinic & $66(89.2)$ & $8(10.8)$ & \\
\hline Private hospital/clinic & $19(90.5)$ & $2(9.5)$ & \\
\hline PHC well equipped & & & $0.007^{* *}$ \\
\hline Best & $53(73.6)$ & $19(26.4)$ & \\
\hline Worst & $57(91.9)$ & $5(8.1)$ & \\
\hline
\end{tabular}


Table 2 (continued)

\begin{tabular}{|c|c|c|c|}
\hline \multicolumn{4}{|c|}{ Factors associated with prolonged delay } \\
\hline \multirow[t]{2}{*}{ Variable } & \multicolumn{2}{|l|}{ Total delay } & \multirow{2}{*}{$\begin{array}{l}\text { p-values } \\
\text { (Fishers } \\
\text { test) }\end{array}$} \\
\hline & Yes & No & \\
\hline Action taken & & & $0.046^{* *}$ \\
\hline Sputum examination & $52(89.7)$ & $6(10.3)$ & \\
\hline Xray & $14(82.4)$ & $3(17.6)$ & \\
\hline Both sputum and Xray & $39(73.6)$ & $14(26.4)$ & \\
\hline Referral & $0(0)$ & $1(100)$ & \\
\hline Others & $5(100)$ & $0(0)$ & \\
\hline \multicolumn{4}{|l|}{ Multivariate analysis } \\
\hline Variable & \multicolumn{2}{|l|}{ Adjusted OR (95\% Cl) } & $p>|Z|$ \\
\hline \multicolumn{4}{|l|}{ Gender } \\
\hline Female & \multicolumn{2}{|l|}{$0.231(0.080-0.670)$} & $0.007^{* *}$ \\
\hline \multicolumn{4}{|l|}{ Occupation } \\
\hline Unemployed & \multicolumn{2}{|l|}{$3.947(1.382-11.274)$} & $0.010^{* *}$ \\
\hline \multicolumn{4}{|l|}{ Marital status } \\
\hline Unmarried & \multicolumn{2}{|l|}{$3.364(0.871-13.001)$} & 0.079 \\
\hline \multicolumn{4}{|c|}{ Second health facility consulted } \\
\hline Private & \multicolumn{2}{|l|}{$0.632(0.177-2.254)$} & 0.479 \\
\hline \multicolumn{4}{|l|}{ Knowledge on TB } \\
\hline No knowledge & \multicolumn{2}{|l|}{$6.904(1.648-28.921)$} & $0.04^{* *}$ \\
\hline \multicolumn{4}{|l|}{ Action taken } \\
\hline Xray and sputum & \multicolumn{2}{|l|}{$2.412(0.904-6.433)$} & 0.904 \\
\hline
\end{tabular}

At multivariate analysis, factors that influenced delay included poor patient knowledge on TB (adjOR 6.904, 95\% CI 1.648-28.921; $\mathrm{p}=0.04$ ) and being unemployed (adjOR 3.947, 95\% CI 1.382-11.274; $\mathrm{p}=0.010$ ) while being female was found protective of delay; adjOR 0.231, 95\% CI 0.08-0.67; $\mathrm{p}=0.007$ ).

\section{Discussion}

This study done at a regional referral hospital determined the magnitude of delay and also the individual and health facility factors associated with the delay. A delay of more than 4 weeks in $82.1 \%$ of the patients was noticed with patient delay being the biggest contributor of the total delay. A similar study done in Uganda found health facility delay as the biggest contributor to the delays [3, 4]. This difference could be due to improvements in the diagnostic capacities of many laboratories especially with the introduction of more sensitive tests including the GeneXpert technology could have shortened the health facility delays. Similar studies in different settings have found patient delay as the commonest type of delay [5-7].

Female gender was associated with lower chances of having total delay, different from findings in a study done in Mukono [8] and other studies [9-12]. The reasons for this could be that the females normally have better health seeking behaviors than their male counterparts. Men tend to neglect symptoms until the disease reaches a serious stage, by which time they tend to go directly to public health services without first visiting private health practitioners $[13,14]$.

Being unemployed in this study was associated with higher odds of having prolonged delay. This could be explained by the financial challenges the unemployed people go through to transport themselves to the diagnostic health facilities and later on pay for their care.

Lack of knowledge was a big predictor of prolonged delay. Our findings are similar to those in the study done in Kampala, Mukono and Wakiso [3, 4] where education was found to be a predictor of delay. Lack of information on TB has been found to be associated with delay in studies done elsewhere in East Africa [15].

As in previous studies $[10,16]$, there was a strong relation between having a second consultation and total delay similar to our results after bivariate analysis, which was not the case at multivariate analysis. Prior attendance to a clinic or second consultation was also 
found to be a predictor of delay in a study done in Ethiopia [17].

Over half, 79 (58.7\%) of the clients were started on TB treatment a day or more after diagnosis. The policy recommended by the World Health Organization is that treatment be initiated on the same day that the diagnosis is made [18]. Doing this would help cut the cycle of infection and also ensure the initial default rates are reduced as some patients might not return to start treatment.

\section{Limitation}

Recall bias during the interviews was a limitation. We allowed enough time for careful probing and used available records for missing information. Also referral patterns of the patients were not ascertained i.e. how many of the patients were referred by the lower health facilities and how many were self-referred.

\section{Abbreviations}

TB: tuberculosis; HIV: human immunodeficiency virus; WHO: World Health Organization; HCP: health care provider; IRB: Institutional Review Board.

\section{Acknowledgements}

The authors wish to thank the staff at Mbale Regional Referral Hospital that took part in the study, particularly the Research Assistants that helped interview tuberculosis patients. The Management of Mbale Regional Referral Hospital is acknowledged.

\section{Authors' contributions}

WM and RB were involved in the development of the proposal. WM carried out field work. WM, SK, and JL undertook data analysis. WM, SK, JL, EB, AK, EM and $\mathrm{RB}$ drafted the manuscript and approved the final draft. All authors read and approved the final manuscript.

\section{Funding}

This study was funded using Authors' personal resources

\section{Availability of data and materials}

The dataset generated during and/or analysed during the current study are available from the corresponding author on reasonable request.

\section{Ethics approval and consent to participate}

All respondents provided written informed signed consent prior to data collection. The study was approved by the Institutional Ethics Review Boards at International Health Sciences University and Mbale Regional Referral Hospital.

\section{Consent for publication}

Not applicable.

\section{Competing interests}

The authors declare that they have no competing interests.

\footnotetext{
Author details

${ }^{1}$ Makerere University Lung Institute, Makerere University College of Health Sciences, Kampala, Uganda. ${ }^{2}$ Department of Medical Microbiology, Makerere University College of Health Sciences, Kampala, Uganda. ${ }^{3}$ Institute of Public Health and Management, International Health Sciences University, Kampala, Uganda. ${ }^{4}$ School of Biotechnology and Laboratory Sciences, Makerere University, Kampala, Uganda. ${ }^{5}$ School of Public Health, Makerere University College
}

of Health Sciences, Kampala, Uganda. ${ }^{6}$ National Tuberculosis and Leprosy Program, Ministry of Health, Kampala, Uganda. ${ }^{7}$ School of Public Health, St. Augustine International University, Kampala, Uganda.

Received: 28 May 2019 Accepted: 7 September 2019 Published online: 18 September 2019

\section{References}

1. World Health Organization. WHO global tuberculosis report 2018. Pharmacological reports. Geneva: World Health Organization; 2018.

2. World Health Organization. Global tuberculosis report 2016.

3. Kiwuwa MS, Charles K, Harriet MK. Patient and health service delay in pulmonary tuberculosis patients attending a referral hospital: a crosssectional study. BMC Public Health. 2005;5(1):122.

4. Buregyeya E, Criel B, Nuwaha F, Colebunders R. Delays in diagnosis and treatment of pulmonary tuberculosis in Wakiso and Mukono districts, Uganda. BMC Public Health. 2014;14(1):586.

5. Mesfin MM, Newell JN, Walley JD, Gessessew A, Madeley RJ. Delayed consultation among pulmonary tuberculosis patients: a cross sectional study of 10 DOTS districts of Ethiopia. BMC Public Health. 2009;9:53.

6. Sherman LF, Fujiwara PI, Cook SV, Bazerman LB, Frieden TR. Patient and health care system delays in the diagnosis and treatment of tuberculosis. Int J Tuberc Lung Dis. 1999;3:1088-95.

7. Odusanya OO, Babafemi JO. Patterns of delays amongst pulmonary tuberculosis patients in Lagos, Nigeria. 2004. http://www.biomedcentral. com/1471-2458/4/18

8. Oola J. Factors influencing delayed diagnosis of tuberculosis in Mukono District, Uganda. 2001. http://dspace3.mak.ac.ug/handle/10570/1987. Accessed 14 May 2019.

9. Yamasaki-Nakagawa M, Ozasa K, Yamada N, Osuga K, Shimouchi A, Ishikawa N, et al. Gender difference in delays to diagnosis and health care seeking behaviour in a rural area of Nepal. Int J Tuberc Lung Dis. 2001:5(1):24-31.

10. Needham DM, Foster SD, Tomlinson G, Godfrey-Faussett P. Socio-economic, gender and health services factors affecting diagnostic delay for tuberculosis patients in urban Zambia. Trop Med Int Health. 2001;6:256-9.

11. Pronyk PM, Makhubele MB, Hargreaves JR, Tollman SM, Hausler HP. Assessing health seeking behaviour among tuberculosis patients in rural South Africa. Int J Tuberc Lung Dis. 2001;5:619-27.

12. Karim F, Islam MA, Chowdhury AMR, Johansson E, Diwan VK. Gender differences in delays in diagnosis and treatment of tuberculosis. Health Policy Plan. 2007;22:329-34.

13. Johansson E, Long NH, Diwan VK, Winkvist A. Gender and tuberculosis control: perspectives on health seeking behaviour among men and women in Vietnam. Health Policy. 2000;52:33-51.

14. Galdas PM, Cheater F, Marshall P. Men and health help-seeking behaviour: literature review. J Adv Nurs. 2005;49:616-23.

15. Wandwalo ER, Mørkve O. Delay in tuberculosis case-finding and treatment in Mwanza, Tanzania. Int J Tuberc Lung Dis. 2000;4(2):133-8.

16. Meintjes G, Schoeman H, Morroni C, Wilson D, Maartens G. Patient and provider delay in tuberculosis suspects from communities with a high HIV prevalence in South Africa: a cross-sectional study. BMC Infect Dis. 2008;25:8.

17. Storla DG, Yimer S, Bjune GA. A systematic review of delay in the diagnosis and treatment of tuberculosis. BMC Public Health. 2008;8(1):15.

18. Yimer S, Bjune G, Alene G. Diagnostic and treatment delay among pulmonary tuberculosis patients in Ethiopia: a cross sectional study. BMC Infect Dis. 2005;12:5.

\section{Publisher's Note}

Springer Nature remains neutral with regard to jurisdictional claims in published maps and institutional affiliations. 